\title{
Methodological Approaches to Reducing the Negative Impact of Transport on the Megalopolis Ecology
}

\author{
Dmitry Zavyalov, Nadezhda Zavyalova, Olga Saginova*, Sergey Tinkov \\ Plekhanov Russian University of Economics \\ *Corresponding author. Email: saginova.ov@rea.ru

\begin{abstract}
The article considers the impact of urban transport on the ecology of the megalopolis and public health. Based on the analysis of scientific publications and statistical data, certain systemic problems have been identified that impede the improvement of the urban environment ecology. The basic algorithm of the eco-monitoring system is offered, which makes it possible to assess the effectiveness of measures and the relevance of the regulatory framework aimed at preserving the ecology of the urban environment, ensuring the preservation of human lives.
\end{abstract}

Keywords: Megalopolis ecology, factors of negative impact, transport, monitoring algorithm

\section{INTRODUCTION}

The issues of preserving the environment around the world are dominant in the management of developed countries. The international community has accumulated significant experience in the regulation and control of the environmental situation, methods and technologies that reduce the anthropological burden on the planet. Based on the analysis of the current environmental situation, various approaches, programs, information databases and indicators for assessing the results of activities in this area have been developed and are used. Therefore, the Economist Intelligence Unit (EIU) calculates the Global Livability Index and identifies the most livable cities around the world [1], assigning a rating of relative comfort for more than 30 qualitative and quantitative indicators. The indicators are formed in five categories: stability, health, culture and environment, education and infrastructure. The Environmental Performance Index offered by the Yale Center for Environmental Law and Policy [17], measures the country's achievements in terms of the state of the environment and natural resource management by 32 indicators in 11 categories of issues. These indicators allow at the national level to assess the compliance of countries with the established goals of environmental policy.

Considering the processes of urbanization, their importance for economic and social development, special attention is paid to the issues of reducing the negative impact on the megalopolis ecology. The solution to this problem is associated with a number of complex problems, including ensuring sustainable transport mobility of the population in the megalopolis, the need to create conditions for effective economic activity and comfortable living conditions. To this end, the EU has developed guidelines for planning sustainable urban mobility, supported by funding for related projects, including through the use of the European Regional Development Fund [12].

Despite the efforts of the authorities in most megalopolises to reduce the use of private cars and develop urban public transport and environmentally friendly means of individual transport mobility, the problem of urban pollution as a result of the development of the transport system remains relevant and requires further solution.

The purpose of the article is to consider the problems that prevent the reduction of the impact of development of transport mobility on the ecology of the Moscow agglomeration and develop recommendations for their elimination.

\section{METHODS}

In carrying out the study, scientific publications, regulatory legal acts, strategic planning documents, reference, analytical and methodological materials of Russian, foreign and international organizations, as well as materials of scientific and practical conferences were used. Consideration of the current situation on the negative impact of transport on the environment was carried out on the example of the largest megalopolis of 
Russia (the city of Moscow) and was based on the results of monitoring the level of urban pollution, presented in open sources, allows us to assess the dynamics of the ongoing processes. The focus of the study was directed to the most significant impact factors for the health of the population - the level of air pollution, noise pollution, pollution of water bodies in connection with the development of the transport system in large cities.

The environment in cities and in the adjacent territories is subject to significant negative impact of anthropological factors arising from the activities of industrial, energy and transport facilities. The consequences of the past economic is cumulation of 30 billion tons of production and consumption waste. Decree of the President of the Russian Federation of April 17, 2017 "On the Strategy of Environmental Safety of the Russian Federation for the Period up to 2025. Pollutants accumulate in soil and land, water bodies, flora and fauna, which become a secondary source of pollution, as a result of which the health of the population is significantly worsening. Total greenhouse gas emissions are increasing every year, largely from the combustion of fossil fuels.

Urban transport plays a significant role in this process, influencing air, soil and water pollution, causing noise, vibration and electromagnetic fields. The first publications on the need to reduce the level of air, soil and water pollution in the development of sustainable urban transport mobility in the international scientific community were published at the beginning of the XXI century $[9,[13],[19]$. The main areas of the study related to the issues of reducing the level of noise and pollutant emissions from vehicles with internal combustion engines, organizing the optimal traffic of vehicles, developing technical solutions to reduce the level of noise and vibrations generated by the transport system. A significant number of works are devoted to changes in approaches to planning transport infrastructure in order to reduce environmental pollution, improve the quality of life and reduce transport costs [8]. Special attention of researchers was drawn to the identification of negative factors of influence on the ecology and health of the urban population. Among the most significant the following social and hygienic factors were identified: (1) pollution of the atmosphere, soil cover and water by exhaust gases containing carbon oxides (II) $\mathrm{CO}$ and (IV) $\mathrm{CO} 2$; nitrogen oxides NOx, sulfur oxides SOx, hydrocarbons CxHy, suspended particles [15] ,[18], [20], [2]; (2) the operation of transport infrastructure facilities (gas stations, repair shops, etc.), (3) noise factors [11],[4],[5], vibration and electromagnetic effects of the rolling stock of the subway and urban railways [[14], 23, 7], which ultimately affects the health of people in cities. In recent years, the studies have focused on implementation of information technologies and systems that ensure optimal traffic management and control over the environmental performance of the urban environment.

For Moscow and the Moscow agglomeration, preserving the environment is one of the priority tasks, ensuring comfortable living and safety for modern people and future generations. Ecological doctrine of Moscow (Environmental doctrine of the city of Moscow (as amended on October 25, 2011) was adopted back in 2005 and is focused on creating a comfortable living environment in the city, preventing diseases caused by unfavorable environmental conditions, and creating conditions for the sustainable development of the city. The main directions for ensuring environmental standards are focused on: (1) reducing air pollution; (2) reducing motor vehicle emissions on motorways; (3) reducing the area of urban areas exposed to noise effects of transport; (4) reduction of the area of territories that are subject to the negative impact of the city's transport system; (5) reduction of emissions of untreated water runoff, including surface runoff, contaminated with chemicals used in road surface treatment; (6) preservation and protection of the "green" zones of the city, protected natural and recreational areas; (7) restoration of biodiversity in the territory of the city, and etc. To reduce the anthropogenic impact, the city authorities are guided by introduction of waste-free technologies, construction and reconstruction of treatment facilities, elimination of unauthorized disposal fields, use of vehicles with electric motors, development of personal mobility equipment, and etc.

Implementation of goals and plans for preservation and improvement of the ecological situation in the city is possible only if there is a program that includes regulations and methods for monitoring the situation according to indicators that maximally reflect the degree of ecological safety of the environment for taking radical measures to prevent the deterioration of the ecological situation in the city.

\section{RESULTS}

According to the data of the social and hygienic monitoring of Rospotrebnadzor, among the main groups of factors influencing the health of the population, socioeconomic factors, sanitary and hygienic factors and lifestyle factors are distinguished. The complex chemical 
load due to chemical pollution of food, drinking water, atmospheric air and soil currently has a steady downward trend - Figure 1. The biological load caused by microbiological contamination of food, drinking water and soil remains high, but rather stable. The impact of physical factors due to increase in noise exposure from vehicles and electromagnetic radiation (from mobile telephone communications), radiation load from medical diagnostic studies has been constantly increasing since 2014, and only in 2019 a decrease was recorded.

Despite the responsibility of the state to regulate environmental issues (Federal Law of the Russian Federation of May 4, 1999, No. 96-FZ (as amended on July 29, 2018) "On the protection of atmospheric air" (as amended on December 8, 2020): https://docs.cntd.ru/) (On the state of sanitary and epidemiological well-being of the population in the Russian Federation in 2020: State report. Moscow: Federal Service for Supervision of Consumer Rights Protection and Human Welfare, 2021, $256 \mathrm{p}$. emissions from mobile pollution sources continue to grow, as shown in Figure 2.

A significant decrease in polluting emissions was observed only in 2019-2020, which was largely determined by the current restrictions in the context of a pandemic, as well as the influence of the warm winter of 2019/2020, which allowed energy enterprises to work not at full capacity.

In Moscow in the winter period of 2019-2020, the concentration of carbon monoxide was $28 \%$ lower, nitrogen dioxide - by $22 \%$, sulfur dioxide - by $39 \%$ than in the same winter period in 2018-2019 [16]. However, with restoration of the city's vital activity in 2021, there

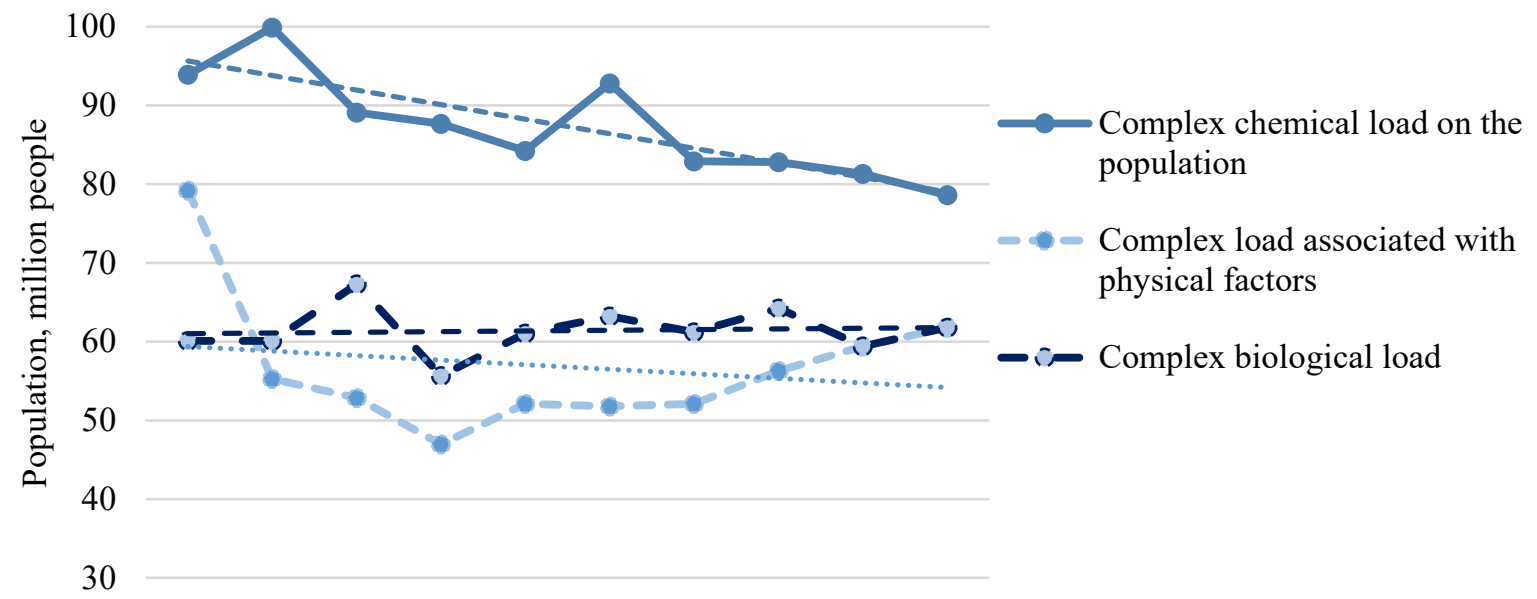

2011201220132014201520162017201820192020

Source: [17]

Figure 1 The size of the population of the Russian Federation exposed to the complex of sanitary and hygienic factors for the period of 2011-2020.

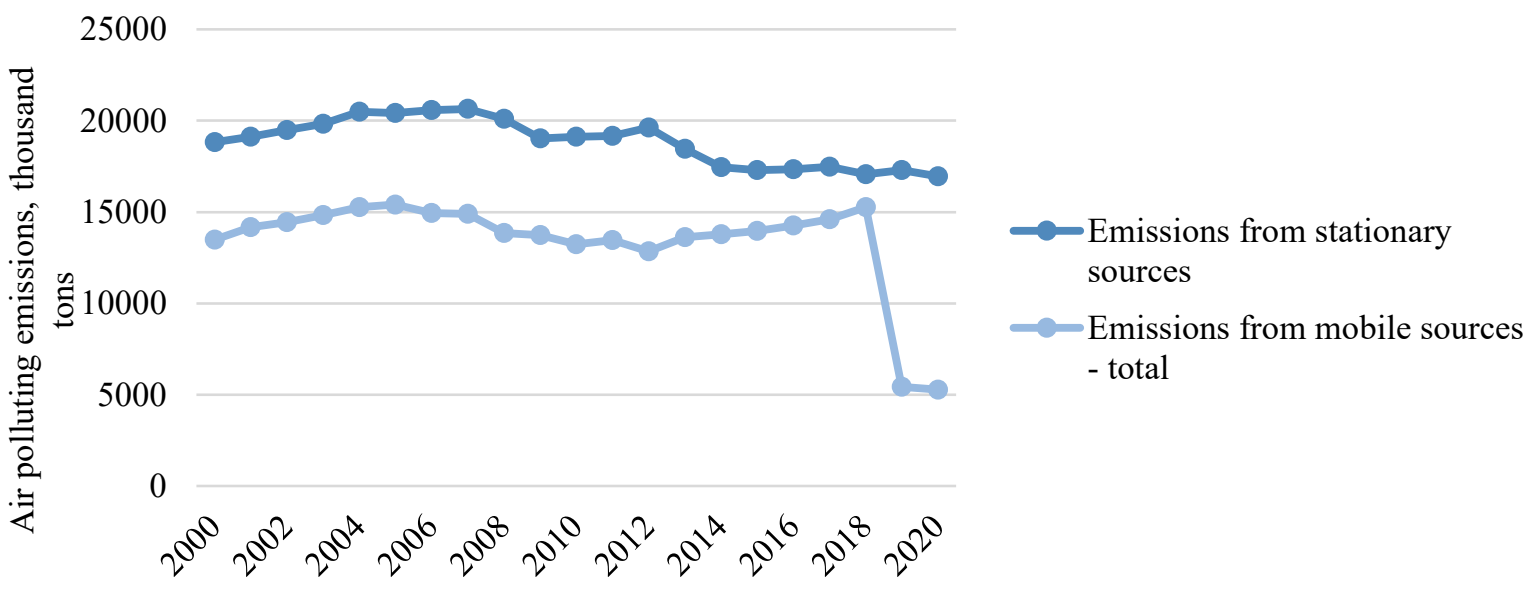

Source: [17]

Figure 2 The volume of emissions of pollutants into the atmosphere 
is again a short-term excess of the WHO recommended values for the content of pollutants in the atmosphere, the level of which depends on the geographic location of the district, the season, weather conditions, and traffic density.

The problem of noise pollution, which affects people's health, reducing concentration, working capacity, increasing irritability, and etc., is currently relevant. The noise level emanating from major highways can reach 90-95 dB and depends on the traffic intensity, speed and composition of the stream (the number of trucks) [13]. According to the monitoring results in Moscow, the largest number of complaints about noise pollution comes from residents in connection with construction works and vehicles - Table 1. Wherein, in the territories adjacent to residential buildings of the first line of development from highways, the number of complaints from Moscow residents about high noise levels in 2020 increased compared to 2016 by almost 4 times - Table 2.

Table 1. Reasons for applying for noise pollution, number of statements

\begin{tabular}{|c|c|c|c|c|c|}
\hline Reason for complaints & $\begin{array}{l}20 \\
16\end{array}$ & $\begin{array}{l}20 \\
17\end{array}$ & $\begin{array}{l}20 \\
18\end{array}$ & $\begin{array}{l}20 \\
19\end{array}$ & $\begin{array}{l}20 \\
20\end{array}$ \\
\hline & & 13 & 10 & 20 & 18 \\
\hline Construction works & 48 & 2 & 7 & 9 & 0 \\
\hline Road transport & 16 & 61 & 60 & 29 & \\
\hline Railway transport & 6 & 12 & 10 & 3 & 4 \\
\hline Road repair works & 6 & 11 & 6 & 4 & 7 \\
\hline Industrial enterprise & 5 & 10 & 2 & 2 & \\
\hline $\begin{array}{l}\text { Generator set at construction } \\
\text { sites }\end{array}$ & 1 & 4 & 4 & 7 & 2 \\
\hline Generator set & 7 & 3 & 1 & 3 & 1 \\
\hline Other sources & 1 & 5 & 1 & 3 & \\
\hline $\begin{array}{l}\text { Loading and unloading works } \\
\text { of built-in and attached stores }\end{array}$ & 1 & 3 & 2 & 1 & \\
\hline
\end{tabular}

Source: Portal of open data of the Government of Moscow
Urban traffic in Moscow continues to grow even at night, as a result of which the conflict of interests of residents and drivers of motorized vehicles intensifies. This requires consideration of (1) vehicle noise control; (2) administrative sanctions for movement of cars and motorcycles with dismantled or modified engine exhaust systems or with loud music; (3) improving technologies for road surface, (4) limiting the movement of trucks in the area of residential buildings, (5) expanding noiseprotective green spaces and creating noise-protective barriers, considering the terrain.

Table 2. Noise pollution complaints in the territories of various categories, the number of applications

\begin{tabular}{|l|r|r|r|r|r|}
\hline \multicolumn{1}{|c|}{ Territories } & 2016 & 2017 & 2018 & 2019 & 2020 \\
\hline $\begin{array}{l}\text { Territories directly } \\
\text { adjacent to } \\
\text { residential } \\
\text { buildings }\end{array}$ & 4 & 7 & 19 & 14 & \\
\hline $\begin{array}{l}\text { Territories adjacent } \\
\text { to hotels and } \\
\text { hostels }\end{array}$ & & 1 & 1 & 2 & 1 \\
\hline $\begin{array}{l}\text { Territories adjacent } \\
\text { to buildings of } \\
\text { hospitals and } \\
\text { sanatoriums }\end{array}$ & 100 & 267 & 187 & 260 & 390 \\
\hline $\begin{array}{l}\text { Territory adjacent } \\
\text { to residential } \\
\text { buildings on the } \\
\text { first line of } \\
\text { development from } \\
\text { highways }\end{array}$ & & & & & \\
\hline
\end{tabular}

Source: Portal of open data of the Government of Moscow

An important task for Moscow is to conserve water resources and soil cover. Uncontrolled (poorly controlled) sources of pollution of water bodies include surface washout through storm sewers and drains of residential areas, water transport, recreational areas and unorganized recreation areas of the population near water bodies, improper storage and disposal of chemicals and solid waste, urban infrastructure, vehicles, the results of

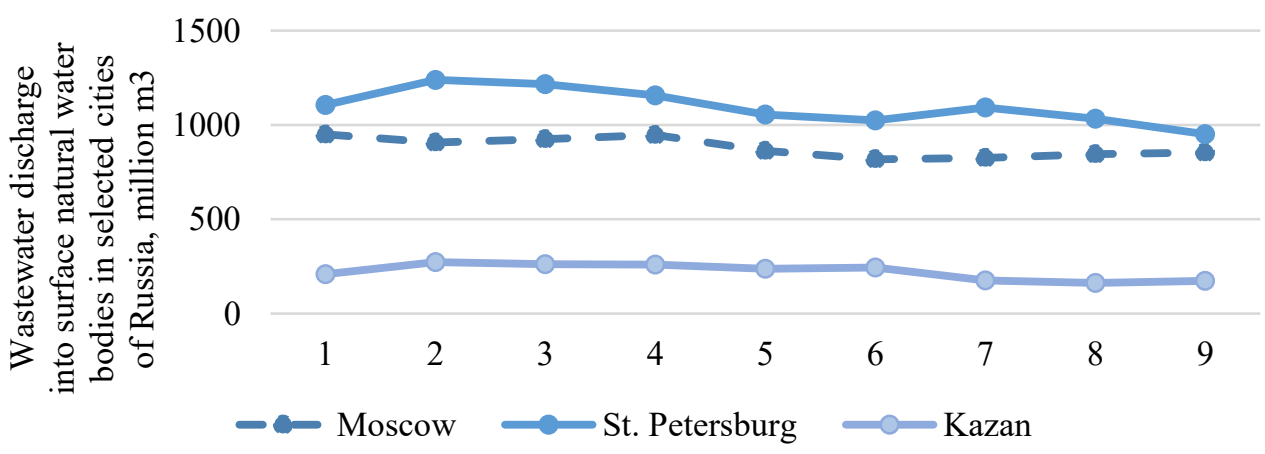

Source: State report "On the state and use of water resources of the Russian Federation in 2018". - M.: NIAPriroda, 2019.- 290 p. https://rosstat.gov.ru/folder/13721

Figure 3 Dynamics of wastewater discharge into surface natural water bodies in selected cities of Russia 


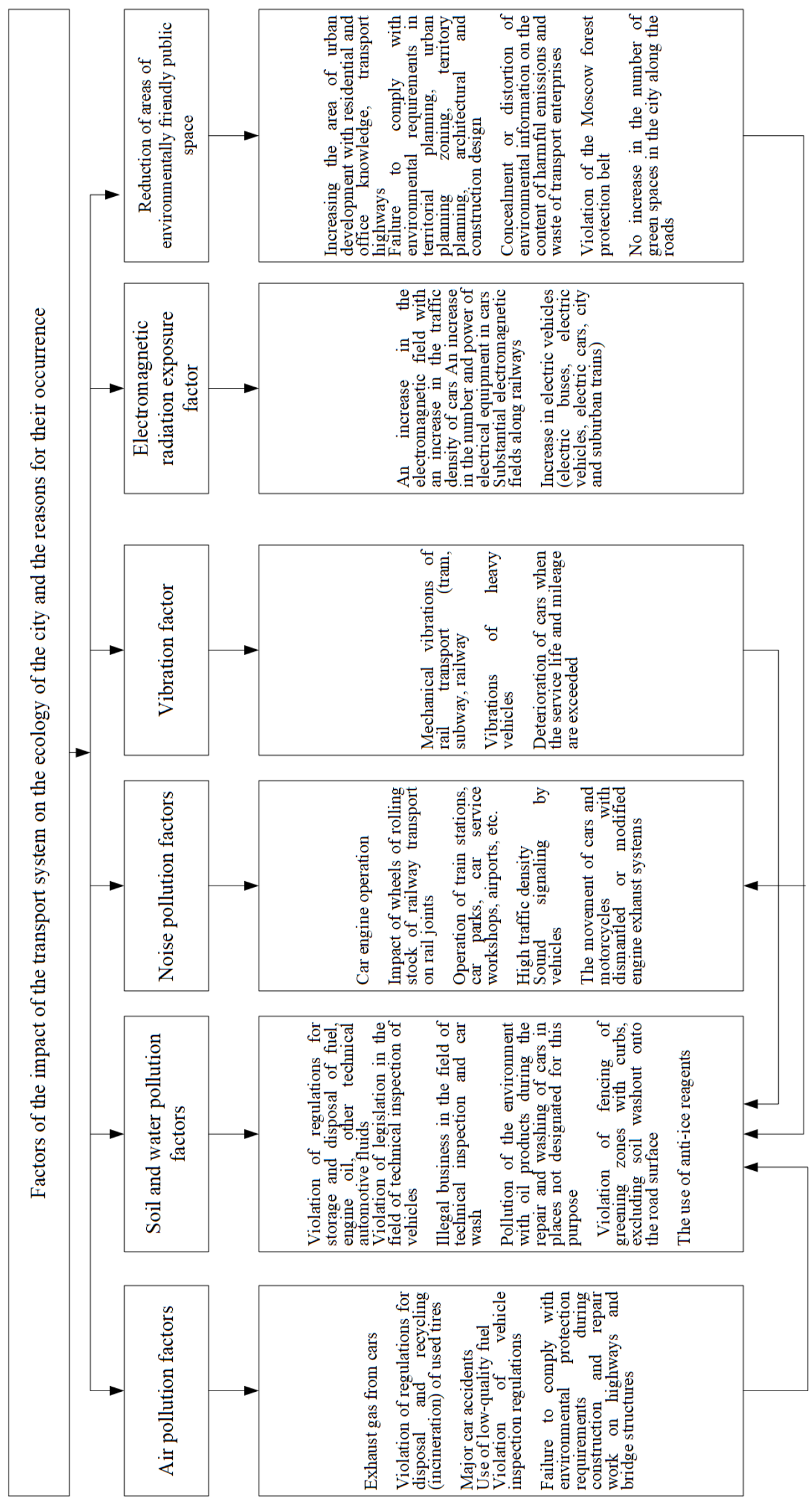

Figure 4 Factors of influence of the transport system on the city ecology. 
salvo discharges in case of technological accidents, and etc.

Among urban agglomerations, Moscow and St. Petersburg have the largest total volumes of polluted wastewater discharge into natural water bodies (Figure $3)$.

A significant impact on the part of the city's transport system on soil degradation and water pollution occurs due to violations of legislation in the field of technical inspection of cars, which leads to increase in emissions of pollutants into the atmosphere, illegal business in car maintenance, use of reagents for cleaning urban roads and sidewalks. The relationship between air pollution and presence of suspended particles (PM) in it and pollution of the soil cover and water surface shall be noted. PM content in the air in the form of dust and droplets suspended in the air (aerosols) is the most dangerous in the city, settling on water and soil, increasing the negative impact on natural objects and human health. Similarly, such a relationship exists between other anthropogenic factors (Figure 4).

\section{DISCUSSION}

Despite the fact that the problem of preserving the environment attracts special attention of the scientific community, public organizations and government agencies in most countries, fears of serious climatic changes and the risks of causing irreparable harm to the health of the population due to the impossibility of selfhealing of the ecology of urban agglomerations from the impact of anthropogenic factors are constantly growing. In this regard, special attention is paid to monitoring issues, and the purpose of such monitoring is not only to determine the sources of environmental pollution and assess the factual state, but to identify trends in ongoing changes, to form possible scenarios for development of the situation to prevent the consequences of the impact of human activities on the environment.

With development of information technologies and systems, control over the state of the environment in Moscow has acquired a background character and has become an integral part of the overall monitoring system of the megalopolis. The system of environmental monitoring in Russia has evolved from legal and regulatory regulation, formation of a set of observation techniques to the actual conduct of observations.

However, the study showed that the following significant problem remains:

- insufficient elaboration of existing methods of managing the risks of air pollution impact on human health and the environment. The regulatory framework provides guidance on assessing public health risk from exposure to chemicals (Order of August 7, 2018 No. 352 of the Ministry of Natural
Resources and Environment of the Russian Federation "On Approval of the Procedure for Inventorying Stationary Sources and Emissions of Harmful (Polluting) Substances into the Air, Correcting its Data, Documenting and Storing Data Obtained as a Result of such Inventories and Adjustments" (as amended on September 17, 2019). Electronic fund of legal and regulatory and technical documents:

https://docs.cntd.ru/document/542630875), which is conceptual in nature, as well as a methodology for conducting an inventory of emissions that pollute the environment into the atmosphere for road transport enterprises (by calculation method) (1998). This technique was developed more than 20 years ago and requires updating the specific emissions of pollutants at idle speed, during warming up the movement of cars, considering the change in the car park and fuel characteristics;

- a significant problem is the lack of plans for systemic control by supervisory authorities of the actual quality of fuel, which is extremely necessary in conditions when, in addition to state standards, technical specifications (TU) and organization standards (STO) are in effect;

Currently, the user of natural resources does not have an obligation to carry out independent or with involvement of the specialized accredited laboratory of environmental control over the content of vehicle emissions. At the legislative level, its implementation was provided during implementation of the technical inspection of vehicles. However, the National Duma of the Russian Federation is considering a draft document on the non-obligation to pass a technical inspection for individuals, which may come into force by the end of 2021, which can significantly worsen the environmental situation in the megalopolis;

information on environmental pollution is presented on the Mosecomonitoring website (Mosecomonitoring website: https://mosecom.mos.ru/karta) and on many other electronic resources, for example, on the Greenpeace website (Greenpeace website https://maps.greenpeace.org/air/lite/), on the World Air Quality Index (WAQI) project website, "Fresh air", BreezoMeter and others, which together provide information on the level of pollution in real time or in a period not exceeding 1 year. Despite the abundance of sources, the integration of data for analysis seems to be very difficult due to the lack of uniform standards for the data provided and uniform approaches to monitoring for all factors affecting the environment and health of the population of the megalopolis. On the portal "Open Data" in Moscow the provided data on the level of pollution of the atmosphere and soil are not informative and cannot be analyzed, and there are no data on the level of pollution of open water bodies. 


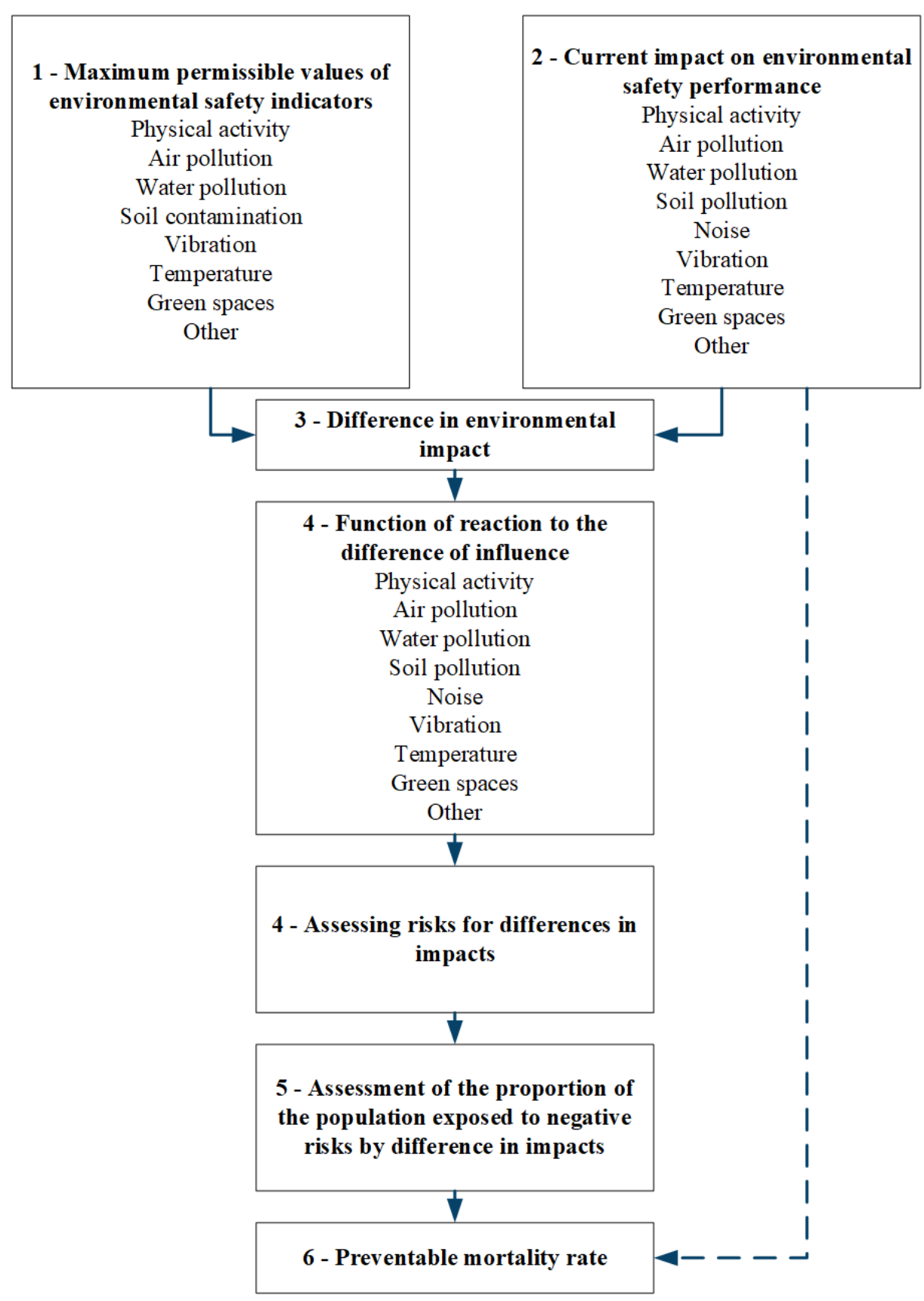

Figure 5 Algorithm for the analysis of factors affecting the ecology of territories and human health.

The city information system for environmental monitoring, including information blocks on environmental legislation, including information blocks on legislation in the field of ecology, including in relation to vehicles, maximum permissible values of pollutants, sources of which are vehicles, could help to reduce the negative impact of the transport system on the ecology of the megalopolis and human health, as well as an information resource reflecting an algorithm for a comprehensive assessment of factors influencing the environment and human health in cities. The basis of such a resource shall be the following data: (1) the permissible level of impact of each of the factors on the environment accordingly; (2) the current level of negative environmental impact; (3) difference in exposure between recommended and current exposure levels; (4) formation and calculation of the exposure response function that quantifies the relationship between exposure and mortality; (5) an estimate of the proportion of the population exposed to the negative risks of the difference in impacts; (6) an estimate of the level of preventable mortality (Figure 5).

The system shall provide for the possibility of applying filters in the context of the time interval, administrative districts and districts of the city, factors of anthropogenic load that have a significant impact on the ecology of the urban environment. 


\section{CONCLUSION}

Information about the measures taken to protect the ecology of the city is very important for the public. The resource created on the basis of the portal of the Moscow Government will ensure the transparency of the information field on the ecology of the city thanks to uniform standards for provision of information, will be able to attract a wide circle of the public to identify violations of pollutants in the megalopolis and create conditions for preserving the ecology of the city and preventing destructive anthropogenic factors on human health.

\section{REFERENCES}

[1] A report by The Economist Intelligence Unit. https://www.eiu.com/n/campaigns/the-globalliveability-index-2021-download-success.

[2] F. Amato, M. Pandolfi, T. Moreno et al, Sources and variability of inhalable road dust particles in three European cities, Atmospheric Environment, 45(37) (2011) pp. 6777-6787.

[3] A. D. May, S. Shepherd, P. Pfaffenbichler, G. Emberger, The potential impacts of automated cars on urban transport: An exploratory analysis Transport. Policy, 98 (2020) pp. 127-138. DOI: https://doi.org/10.1016/j.tranpol.2020.05.007.

[4] J. Dratva, H.C. Phuleria, M. Foraster, J.M. Gaspoz, D. Keidel, N. Künzli, L.-J. Sally Liu, M. Pons, E. Zemp, M.W. Gerbase, et al. Transportation noise and blood pressure in a population-based sample of adults. Environ. Health Perspect. 120 (2011) pp. 5055. DOI: https://doi.org/10.1289/ehp.1103448.

[5] Environmental noise guidelines for the European Region (2018). World Health Organization 2018 https://www.euro.who.int/ru/healthtopics/environment-and-

health/noise/publications/2018/environmentalnoise-guidelines-for-the-european-region-2018.

[6] H. Khreis, A. D. May, M. J. Nieuwenhuijsen, Health impacts of urban transport policy measures: A guidance note for practice, Journal of Transport \& Health, 6 (2017) pp. 209-227. ISSN 2214-1405. DOI: https://doi.org/10.1016/j.jth.2017.06.003.

[7] C. Iglesias-Merchan, R. Laborda-Somolinos, S. González-Ávila, R. Elena-Rosselló, Spatiotemporal changes of road traffic noise pollution at ecoregional scale. Environmental Pollution, 286 (2021) DOI: https://doi.org/10.1016/j.envpol.2021.117291

[8] J. Legaspi, S. V. Bhada, P. Mathisen and J. DeWinter, "Smart City Transportation: A
Multidisciplinary Literature Review," 2020 IEEE International Conference on Systems, Man, and Cybernetics (SMC), 2020, pp. 957-964. DOI: https://doi.org/10.1109/SMC42975.2020.9283471.

[9] M. Jacyna, M. Wasiak, K. Lewczuk, K. Grzegorz, Noise and environmental pollution from transport: decisive problems in developing ecologically efficient transport systems. Jveinternational LTD. Journal OF VIBROENGINEERING, 19(7) (2017) ISSN $\quad 1392-8716 \quad 5639 \quad 2697$ DOI: https://doi.org/10.21595/jve.2017.19371

[10] J. I. Levy, J. J. Buonocore, K. Von Stackelberg Evaluation of the public health impacts of traffic congestion: a health risk assessment. Environmental Health, 9(65) (2010) pp. 1-12.

[11] A. Recio, C. Linares, J.R. Banegas, J. Díaz, Road traffic noise effects on cardiovascular, respiratory, and metabolic health: An integrative model of biological mechanisms. Environ. Res. 146 (2016) pp. 359-370. DOI: https://doi.org/10.1016/j.envres.2015.12.036.

[12] Sustainable development in the European Union. Monitoring report on progress towards the SDGs in an EU context. 2021 edition. Luxembourg: Publications Office of the European Union, 2021.

[13] N.V. Bakaeva, D.V. Matyushin, T.M. Novikova. Assessment of acoustic pollution of the urban environment on the basis of the biosphere compatibility indicator, Construction and reconstruction, 1(57) (2015) pp. 74-83.

[14] V.A. Vasiliev, V.K. Ksenofontova. Noise of Road Transport, Noise Theory and Practice, 1(19) (2020) pp. 66-76.

[15] Influence of road transport on pollution of the roadside zone with heavy metals, Problems of operation and maintenance of transport and process machines: Reports of the international scientific and technical conference. Tyumen: Felix, 2006, pp. 149152.

[16] Moscow City Environmental Report 2020 The government of Moscow. The complex of the municipal economy of the city of Moscow. http://www.dpioos.ru

[17] Sustainability Index (yale.edu). https:/epi.yale.ed

[18] S.A. Kleshch, A.P. Dorogovtsev, Negative impact of road transport on the soil, Bulletin of the Cherepovets State University, 4 (2008) pp. 101-105.

[19] A.A. Kovrigin, A.S. Marshalkovich, Assessment of the impact of emissions from moving vehicles to ensure the environmental safety of citizens' life, 
Construction: Science and Education, 3 (2016) http://nso-journal.ru. DOI: https://doi.org/10.22227/2305-5502.2016.3.5.

[20] N. E. Kosheleva, M. F. Dorokhova, N. Yu. Kuzminskaya, A. V. Ryzhov, N. S. Kasimov, Influence of vehicles on the ecological state of soils in the Western Administrative District of Moscow, Moscow University Bulletin. Series 5. Geography, 2 (2018) pp. 16-27.

[21] K.V. Pankratova, Vibration field of St. Petersburg, GIAB, 4 (2016) pp. 211-216. 